\title{
David Oliver: What to do about end of life scare stories
}

\author{
David Oliver consultant in geriatrics and acute general medicine, Berkshire
}

A recent Daily Mail front page screamed, "Over 75? Sign here if you' re ready for death." It was referring to GPs planning care for patients with long term conditions who are at high risk of admission to hospital, including discussion of DNACPR (do not attempt cardiopulmonary resuscitation).

A third of hospital patients are in their last year of life. ${ }^{2}$ Frailty, many long term conditions, and nursing home residence confer reduced life expectancy. So where's the scandal?

Regarding the Liverpool care pathway for dying people, the Mail story described "a practice whereby foods and fluids are withdrawn from patients close to death . . . they are usually sedated . . . to free up beds or claim financial incentives."

This warped interpretation recycled earlier Mail reportage that was instrumental in driving the Neuberger review and the pathway's demise. ${ }^{3}$ But palliative care guidance in English hospitals has retained the pathway's positive principles of openly discussing the dying phase and attempting to reduce pain and indignity.

The National Institute for Health and Care Excellence (NICE) has published new draft guidelines on end of life care. ${ }^{4}$ The Daily Telegraph responded, "The new end of life care guidelines are lethal." 5 The story? One doctor, Patrick Pullicino-not a palliative care specialist but a media savvy critic of the Liverpool care pathway_had dismissed NICE's diligent work. The newspaper presented little expert counterview.

The Observer $^{6}$ and the $\mathrm{BBC}^{7}$ have carried more measured analyses, but sensationalism touches a mass circulation nerve, particularly when linked to an emotive subject that readers may be scared to consider or may link to bad family experiences.

Care planning aims to improve choice, support, communication, and control for patients. Advance care plans specific to terminal illness extend to death in a place of the patient's choosing, with minimal use of invasive, distressing, medicalised interventions such as cardiopulmonary resuscitation. ${ }^{8}$ Patients, carers, and charities have helped develop and promote this approach, and it can improve experience and help patients to die in a place of their choosing. ${ }^{9}$
In the National Survey of Bereaved People one in 10 rated quality of care as "poor,"10 and the NHS Ombudsman has investigated many complaints involving terrible experiences. ${ }^{11}$ Both highlight poor care planning and inadequate discussion of dying or pain relief.

Not dying is not an option, but helping people to die as well as possible is. The media narrative could inhibit clinicians from doing the right thing or prevent patients and families from engaging with skilled support.

Clinicians must show more sensitive and compassionate communication, whatever the pharmacological technicalities of symptom relief. We need better, more consistent training and awareness. We also need to challenge the media narrative with success stories, to counter half truths, and to highlight that the alternatives to care planning and palliative care are infinitely worse.

1 Borland S. Over 75? Sign here if you're ready for death. Daily Mail 2015 Apr 26. www dailymail.co.uk/news/article-3056621/Over-75-Sign-ready-death-GPs-ask-older-patientsII-agree-not-resuscitate-order.html.

2 Clark D, Armstrong L, Allan A, et al. Imminence of death among hospital inpatients: prevalent cohort study. Palliat Med 2014;28:474-9.

3 Regnard C. The demise of the Liverpool care pathway: should we ban the highway code because of bad drivers? Age Ageing 2014;43:171-3.

4 National Institute for Health and Care Excellence. End of life care: draft guidelines. 2015 http://bit.ly/1UDsyOD.

5 Pullicino P. The new end of care guidelines are lethal. Daily Telegraph 2015 Aug 3. www. telegraph.co.uk/news/nhs/11779394/The-new-end-of-life-guidelines-are-lethal.html.

6 Henry C, Barnes D, von Abendorff R, Howson C. End of life care needs to be better understood and managed. Observer 2015 Aug 23. www.theguardian.com/theobserver/ 2015/aug/23/the-big-issue-end-of-life-care-assisted-dying.

7 Dreaper J. Care of dying patients still inconsistent and poor. BBC Health News 2015 Sep 4. www.bbc.co.uk/news/health-34144863.

8 The Gold Standards framework. Advance care planning. 2013. www. goldstandardsframework.org.uk/advance-care-planning.

9 Nuffield Trust. The impact of Marie Curie Nursing Service on place of death and hospital use at the end of life. 14 Nov 2012. www.nuffieldtrust.org.uk/publications/marie-curienursing.

10 Office for National Statistics. National survey of bereaved people (VOICES), 2014. 9 July 2015. www.ons.gov.uk/ons/rel/subnational-health1/national-survey-of-bereaved-people-voices-/2014/stb-voices-2014.html.

11 Parliamentary and Health Service Ombudsman. Dying without dignity: investigations into complaints about end of life care. 2015. www.ombudsman.org.uk/_data/assets/pdf_file/ 0019/32167/Dying_without_dignity_report.pdf.

Cite this as: BMJ 2015;351:h4846

๑ BMJ Publishing Group Ltd 2015 